\title{
Air Pollution Mortality in Denmark, Finland, and Sweden
}

\author{
ULLA LEHMIJOKI, Ph.D., University Lecturer \\ Helsinki Center of Economic Research HECER \\ ELENA ROVENSKAYA, Ph.D., Researcher \\ International Institute for Applied Systems Analysis, IIASA, Austria
}

\begin{abstract}
The adverse health consequences of air pollution are of concern currently and there is a fear that these consequences escalate along with economic growth. The effect of economic growth on air pollution deaths is analyzed in Denmark, Finland, and Sweden by applying the Environmental Kuznets Curve approach, according to which economic growth has competing effects on air pollution and related deaths. On the one hand, emissions tend to increase as the scale of economic activity increases, but on the other hand, consumers and firms in richer countries use cleaner goods and adopt cleaner technologies. In Denmark and Finland, the latter effects are stronger, while in Sweden the opposite is true. Therefore, air pollution deaths will decrease in Denmark and Finland but increase in Sweden. Since country's own emissions do not determine air pollution completely, the paper briefly analyzes emissions from the Baltic countries and Russia.
\end{abstract}

Keywords: Air Pollution, Mortality, Economic Growth, Denmark, Finland, Sweden

\section{Introduction}

Air pollution deaths are of considerable concern currently. Exposure to air pollutants has been associated to premature deaths both in short-run studies, in which day-to-day variation in pollution is connected with day-to-day variation in deaths, and in long-run studies, in which individuals have been followed on the cohort basis. Air pollution raises mortality mainly through increases in respiratory and cardiovascular diseases, but skin and lung cancers may also appear. World Health Organization and the Clean Air for Europe-program have recently provided estimates claiming that there is more than 30000 annual air pollution deaths in the European Union; almost 8000 of these deaths occur in the three Nordic Member States (WHO 2004).

In this paper, we investigate the evolution of air pollution deaths in Denmark, Finland, and Sweden. It seems to be a common fear that economic growth will increase the number of these deaths in the future. To discover whether this is the case, we concentrate on the effect of economic growth on air pollution deaths. 
The Environmental Kuznets Curve $(E K C)$ hypothesis suggests that economic growth has three competing effects on environmental degradation (Arrow et al. 1995; Stokey 1998; Cole and Elliot 2003; 2005). First, there is the scale effect which increases degradation since the scale of economic activity increases. Second, there is the composition effect, which decreases degradation because consumers in richer countries are willing and able to pay for cleaner goods. Third, there is the technology effect, which also decreases degradations as the latest, less polluting vintages of machines and goods are adopted and implemented in richer countries (Pasche 2002, Kelly 2003).

In this paper, we provide estimates for air pollution deaths in 2020 in two steps to illustrate the role of the above effects. As the first step, we calculate the Constant Emission Intensity $C E I$ value with the assumption that emissions keep at the current level compared with incomes. This first step shows that deaths would increase in all countries if only the scale effect were present. As the second step, we provide the air-pollution-EKC for 25 European Union countries (EU25), indicating that emissionintensities decrease along with economic growth. The estimated $E K C$ is so steep that air pollution in Denmark and Finland will decrease as the composition and technology effects are together stronger than the scale effect, whereas in Sweden air pollution will increase to some extend. The number of air-pollution deaths will decrease in Denmark and Finland but increase in Sweden respectively.

Air pollution deaths, however, are not completely dictated by a country's own emissions. On the contrary, air pollution is also a transboundary problem as emissions travel large distances and cause adverse effects in other countries. From the Nordic perspective, the countries of interest are the Baltic countries and Russia. All these countries have high air pollution intensities and cause considerable problems in their neighborhoods. However, in 2004 the Baltic countries joined the European Union, which promises that air pollution decreases in the future. On the contrary, Russia may even attract polluting industries thus posing Denmark, Finland, and Sweden under the risk of higher emissions in the future.

The paper is organized as follows: Section 2 introduces the base year data and compares air pollution and death numbers in Denmark, Finland, and Sweden with the European averages. In Section 3, the air-pollution-EKC is estimated and the effect of economic growth on air pollution and deaths is analyzed. Section 4 discusses transboundary air pollution and Section 5 closes the paper. The data is given in the Appendix. 


\section{GDP, Emissions, and Environmental deaths}

Consider the economic and health position in 2000. The summary estimates for shortterm air pollution exposure and deaths in Europe show that there is a significant response in mortality to particulate matter PM and ozone (WHO 2004; 2007). ${ }^{1}$ Pope et al. (2002) have analyzed the effects of long-term $P M$ exposure in the United States in a study, where questionnaires followed individuals from 1982 onwards, making control for other risk sources possible. Their estimates were applied for the European data to derive the effects of long-term exposure; in 2000, the short-term and long-term exposures together induced more than 300000 premature deaths in Europe (WHO 2004). ${ }^{2}$

Although the mortality numbers above refer to several pollutants, most deaths are caused by particulate matter (WHO 2004). Furthermore, since particulates are closely associated with other pollutants, they can be used as an indicator for air pollution. Hence, in this research we measure air pollution by the fine particulate matter $P M_{2.5}$. The data comes from Amann et al. (2004) who report the emissions for EU25. The economic data comes from Heston et al. (2006). The $P M_{2.5}$ emissions are given in kilotons and the economic data in constant international dollars. The data, available for the year 2000, is given in Appendix $A$.

We assume that all emissions are born in economic activities, measured by gross domestic output, GDP. Hence, emissions $E$ can be written as

$$
E=\varnothing \cdot G D P
$$

where $\varnothing=E / G D P$ is the emission-intensity, illustrating how many emission units are associated with every unit of GDP. Emission-intensities vary across countries due to variance in energy sectors as some countries rely on fossil fuels whereas clean energy is available in some others. Different emissions arise from housing and traffic sectors as well. Given the $P M_{2.5}$ emissions and GDPs (Appendix $A$ ) we can derive emissionintensities 0.17, 0.24, and 0.11 for Denmark, Finland, and Sweden. Figure 1 reports these numbers together with the average in EU25, showing that lowest emissionintensity arises in Sweden, whereas Finland is close to the average in EU25.

Air pollution causes several unwanted health consequences from harmless aye irritation to death (Samet et al. 2000, Brunekreef and Holgate 2002, Pope et al. 2002). Hence, we let

$$
D=\eta E
$$

\footnotetext{
${ }^{1}$ Particulate matter $P M$ consists of solid airborne particles of varying size, chemical composition, mainly generated by energy combustion (mobile or fixed site), often also from long-distance sources. Particles are classified according to their maximum diameter size, the main groups of particulate matter are then $P M_{2.5}$ and $P M_{10}$ with particles of maximal diameters 2.5 and $10 \mathrm{~mm}$, respectively.

${ }^{2}$ For methodological issues in epidemiological studies see Chay et al. (2003). For studies on infant mortality, see Chay and Greenstone (2003) and Currie and Neidell (2005). For techniques to derive ountry-level mortality estimates, see Ostro (2004).
} 
where $D$ refers to air pollution deaths and $\eta=D / E$ to deaths per emissions respectively (Appendix $A$ ). The parameter $\eta$ controls for factors such as weather conditions and urbanization, which vary from country to country. The actual exposure depends on these factors. In what follows, we assume that there is no change in these factors during the research period so that $\eta$ is constant in each country. Panel $a$ in Figure 2 shows, however, that differences in $\eta$ across NORD3 and EU25 are considerable; the lowest death numbers per emission unit are seen in Finland, where the rate of urbanization is relatively low and a great deal of the polluting factories are located in rural rather areas. The high value for $\eta$ in Denmark may refer to high transboundary emissions, which increase the deaths relative to domestic emissions.

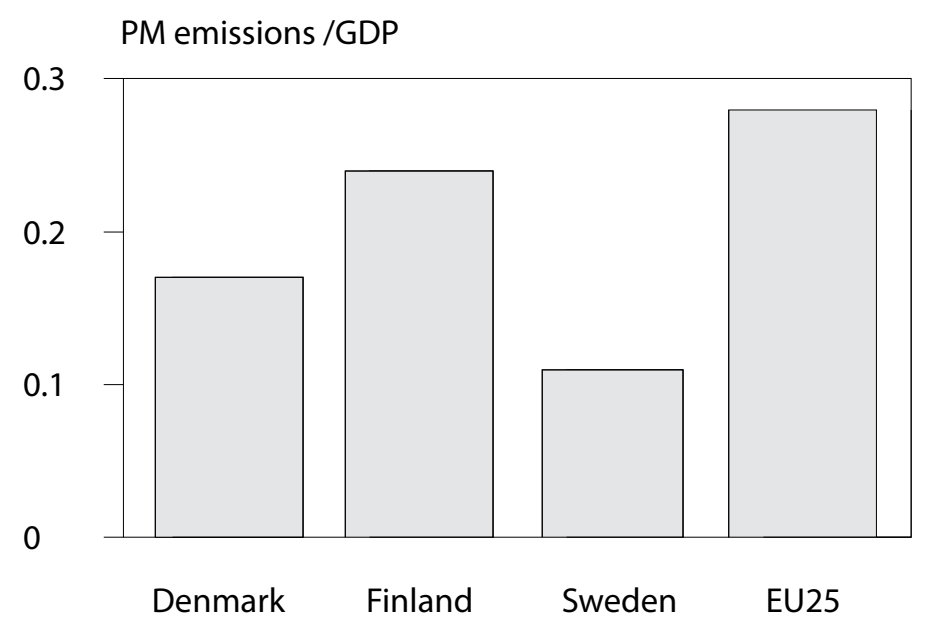

Figure 1. Emissions-intensities in 2000 (kilotons per billion dollars).

a

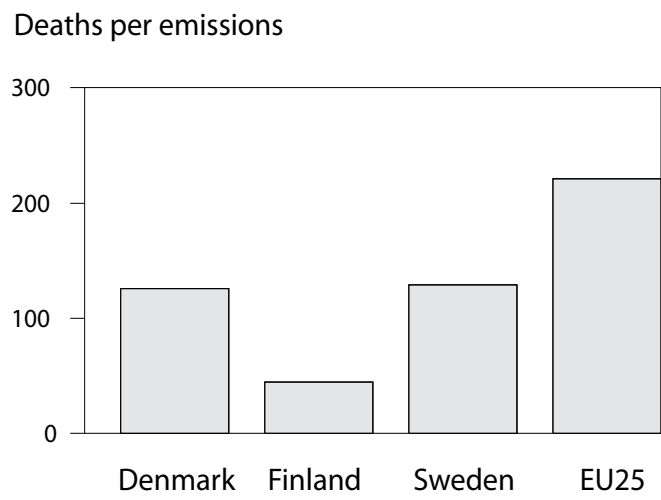

b

Deaths

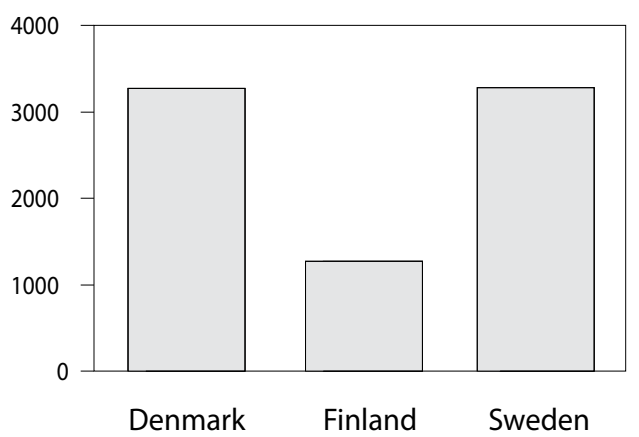

Figure 2. Deaths per emissions (panel a) and the number of air pollution deaths in 2000 (panel $b$ ). 
To collect, equations (2) and (1) show that the number of air pollution deaths is $\eta \cdot \varnothing \cdot G D P$. Panel $b$ in Figure 2 and Table 1 shows these numbers in Denmark, Finland, and Sweden in the base year 2000. The total number of pollution-induced deaths was 348599 in EU25.

\section{Air pollution Deaths and Economic Growth}

Consider now the evolution of the economies from 2000 to 2020. During the past twenty years, the average growth in per capita GDPs (GDPpc) was 1.90, 1.83, and 1.64 percent in Denmark, Finland, and Sweden, implying that GDPpc will almost double from 2000 to $2020{ }^{3}$ Economic growth thus puts emissions and deaths into pressure: if the emission-intensity keeps constant, emissions and pollution-induced deaths grow analogously. Therefore, the Constant Emission Intensity CEI path implies that the number of deaths would almost double in 2020 (Table 1).

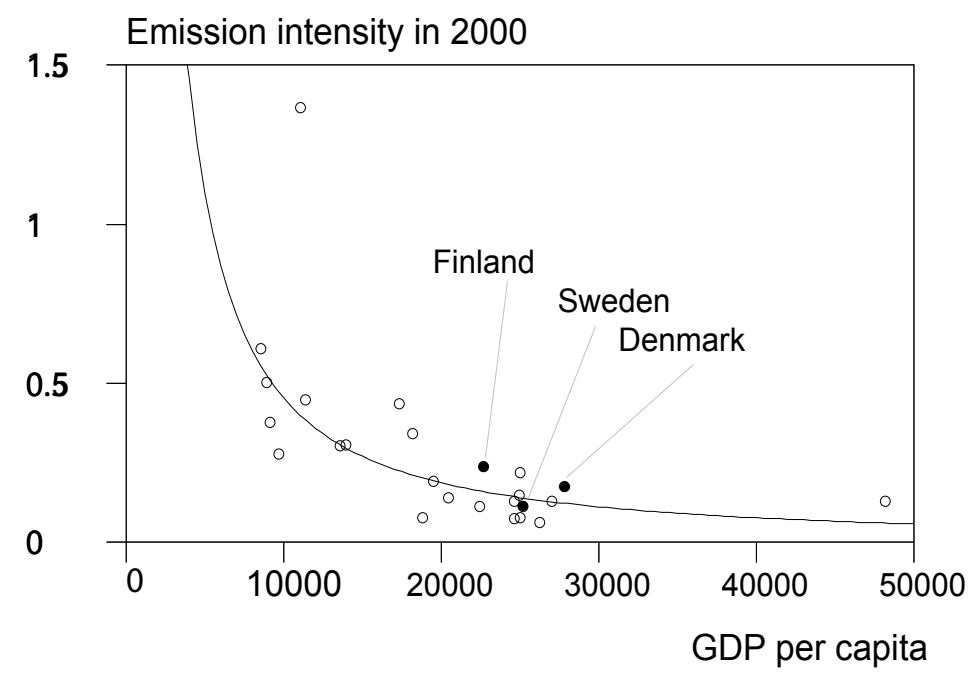

Figure 3. The Environmental Kuznets Curve (EKC) for EU25 in 2000.

However, the Environmental Kuznets Curve hypothesis suggests that emission-intensities vary with economic growth. In particular, they tend to decrease in a sample of relatively rich countries. Thus, one expects to see a downward sloping curve between emission-intensities and per capita incomes. Figure 3 illustrates the emission-intensities as a function of per capita GDP in 2000, indeed showing that, in EU25, the richer countries exhibit much lower emission-intensities than the poorer ones. ${ }^{4}$

\footnotetext{
3 Lehmijoki and Roveskaya (2007) analyzed economic growth, pollution, and deaths in the optimal growth framework.

${ }^{4}$ Some versions of EKC regress emissions per capita against GDPpc. Air pollution, however, is public good, consumed by all in equal amounts and independently of the total number of exposed people. Therefore, per capita emissions are not meaningful here.
} 
The estimated $E K C$ is

$$
\varnothing=56298.77 \cdot \mathrm{GDPpc}^{-1,27} \cdot
$$

The variation of GDPpc explains $55 \%$ of the variation in $\varnothing$. Figure 3 shows that although Denmark, Finland, and Sweden exhibit relative low emission-intensities, they still have potential for further reductions. Applying the predicted per capita GDPs of 40 715, 32 812, and 35035 dollars and equation (3) for Denmark, Finland, and Sweden one derives the emission intensities $\varnothing=0.076$, $\varnothing=0.100$, and $\varnothing=0.092$ for the year 2020 respectively. This indicates that the average annual decrease in emissionintensities will be $3.2 \%$. Obviously, this is challenging. Calculating the total emissions (1) and deaths (2) one derives the (final) $E K C$ prediction for these numbers. The base year situation and the $C E I$ and $E K C$ predictions are presented at Table 1.

Table 1. Emissions and air pollution deaths.

\begin{tabular}{|l|c|c|c|}
\hline Variable & Denmark & Finland & Sweden \\
\hline Emissions & 25.97 & 28.26 & 25.4 \\
\hline Base year & 39.6 & 44.16 & 37.67 \\
\hline Pred. CEI & 17.22 & 18.4 & 30.56 \\
\hline Pred. EKC & 3274 & 1272 & 3284 \\
\hline Deaths & 4993 & 1988 & 4870 \\
\hline Base year & 2170 & 828 & 3951 \\
\hline Pred. CEI &
\end{tabular}

Figure 4 illustrates the results of the $E K C$ analysis above. Both emissions (panel $a$ ) and deaths (panel $b$ ) are given in three bars. The first bar reports the situation in the base year 2000. The next two bars give the $C E I$ and $E K C$ predictions for the year 2020. Figure 4 shows that the scale effect (the difference between the base year and $C E I$ ) is more than offset by the composition and technology effects (the difference of the $C E I$ and $E K C$ bars) in Denmark and Finland, whereas in Sweden the scale effect dominates. ${ }^{5}$ As a consequence, emissions and deaths decrease in Denmark and Sweden but increase in Sweden, although this increase is only modest. Even in Sweden, the $C E I$ would have implied a much higher increase in deaths.

Furthermore, the results above do not give the absolute minimum in emissions and deaths. The $E K C$ emphasizes that adoption and implementation of all available technologies are easier in richer countries. Yet, completely new technologies may arise. This may shift the $E K C$ downwards, implying that the emission-intensity decreases

\footnotetext{
${ }^{5}$ Note that the composition and technology effects, which work in the same direction, are captured together. In this presentation, it is not possible to discriminate between them. Merely, the question is of intuition.
} 
in all countries. European Union launches several programs and uses considerable resources to discover such technologies. Stokey (1998) emphasizes that the $E K C$, such as estimated here, does not arise automatically and governmental actions may be needed. Obviously, the environmental legislation and activities of European Union have played a role for the $E K C$ to arise, even if we are unable to identify this role in the simple approach used here.

Considerable efforts to provide the reliable results of the emission situation in Europe have also taken place, as large-scale models have been constructed to validate data from the Member States. One of these models is the Regional Air pollution Information and Simulation model RAINS, currently GAINS after amended with greenhouse cases. Depending on scenario details, RAINS gives the estimates for emissions 15, 23, and 16 kilotons for Denmark, Finland, and Sweden in 2020. Of these estimates, only Sweden is considerably different from that presented here. This is due to the fact that Sweden has actually exhibited lower than estimated emissions (lies below the curve in Figure 3), mainly due to its efficient energy sector. This advantage may persist, yet is not taken into account in the calculations here.

a

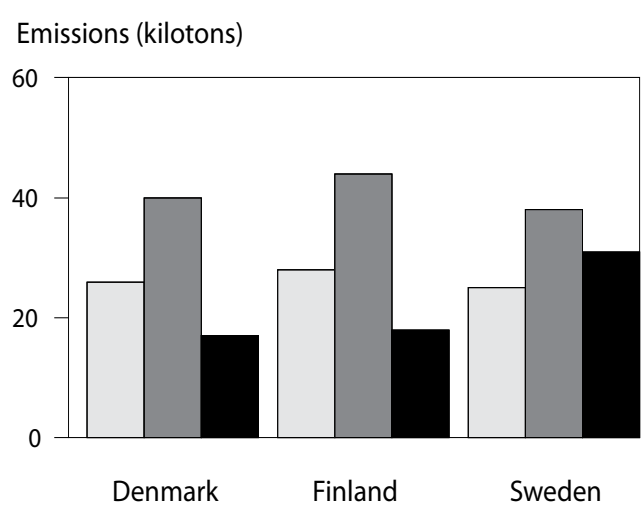

b

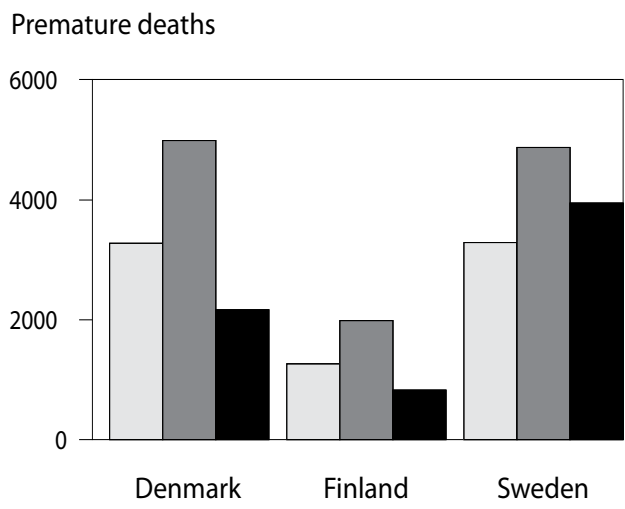

Figure 4. Emissions (panel a) and deaths (panel b) in 2000 (left), CEl prediction (middle) and final EKC prediction in 2020 (right).

\section{Transboundary Air Pollution}

The air pollution mortality is not solely dictated by a country's own emissions. On the contrary, air pollution is also a transboundary problem as emissions can travel long distances and cause adverse effects in other countries.

At the European level, the role of transboundary emissions is important as this densely inhabited continent consists of countries with different emission-intensities. Above all, the emission-intensities in the new $E U$-members are more than twice as big as those 
in the old ones. The closest new $E U$-members are Estonia, Latvia, and Lithuania. Figure 5, panel $a$ gives the emission-intensities in these countries, showing that they are markedly higher than in NORD3 and EU25. The total emissions in the Baltic area accounted to 45.12 kilotons in 2000 . To calculate the predicted values for 2020 , apply the economic growth rates from the past (the average was $3.64 \%$ ) to see that according to the $C E I$ prediction, the total $P M 2.5$ emissions from this area would increase to 84.60 kilotons, yet decrease to 25.42 kilotons in the $E K C$ case. $^{6}$

a

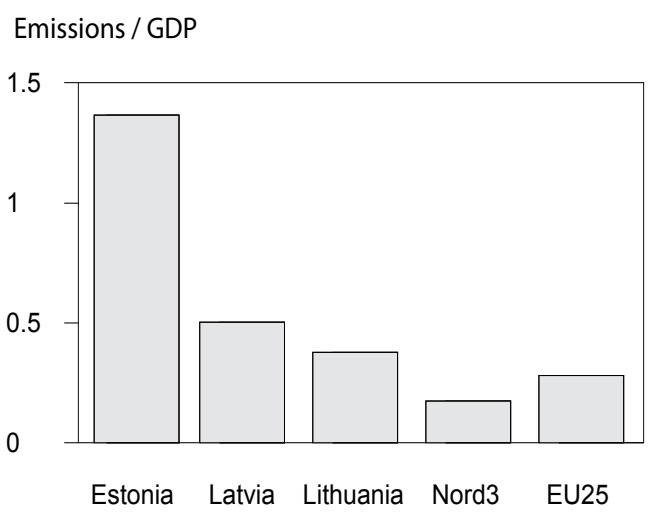

b

Emissions (kilotons)

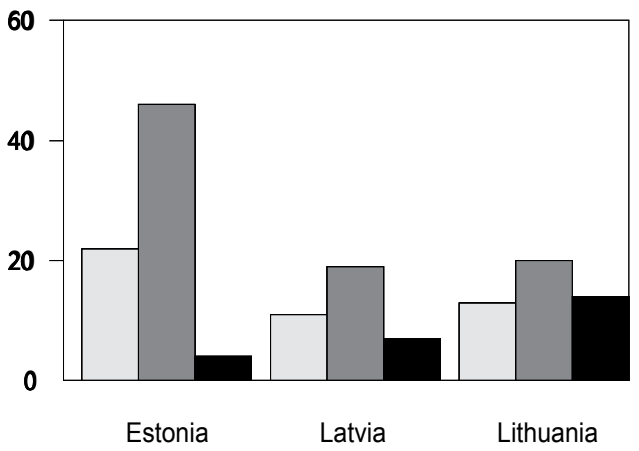

Figure 5. The emission-intensity (panel a) and emissions (panel $b$ ) in 2000 (left), CEI prediction (middle) and final EKC prediction in 2020 (right).

Figure 5, panel $b$ illustrates the emissions in Estonia, Latvia, and Lithuania. The particular interesting case is Estonia, where the average annual economic growth from 1993 to 2000 was as high as $4.6 \%$. If this growth rate continues from 2000 to 2020 , per capita GDP in Estonia increases to almost three-fold, implying a remarkable decrease in the emission-intensity as well. If these growth numbers will realize, Estonia will really be leapfrogging, not only in economic but also in environmental terms. The RAINS-estimates for Latvia and Lithuania are in line with those given here, but our estimate for Estonia is much smaller; it may indeed be too challenging to reach the numbers calculated here. However, both RAINS-estimates and our estimates suggest that transboundary emissions from the Baltic area will decrease.

An alternative origin for long-range problems is Russia, where emissions are considerable in some parts of the country. Given the typical weather conditions, the transboundary emissions are also remarkable, to southern parts of NORD3, in particular. Given that Russia is not associated to European Union, it faces much weaker political and

\footnotetext{
${ }^{6}$ Unfortunately, these countries provide data only since 1993 onwards, which naturally decreases the reliability of the estimates above. The ongoing economic crisis also casts some doubt on the reliability of the predicted high growth numbers in these countries.
} 
legal pressure for emission decreases. Furthermore, the well-known Pollution Havenshypothesis suggests that emission-intensive firms from more strongly regulated countries may migrate to countries where environmental legislation is lax (Cole and Elliot 2003 and 2005). In the future, such migration may take place from European Union to Russia and the western parts of the country are the most likely location, the migrating firms thus sending some additional emissions to the area of NORD3.

\section{Conclusions}

This paper investigates the evolution of air pollution deaths in Denmark, Finland, and Sweden from 2000 to 2020. The focus is in the role of economic growth. We show that even if the increase in the scale of economic activity tends to increase environmental deaths, richer countries show lower pollution rates per income. Therefore, the net effect is that air pollution deaths are expected to decrease in Denmark and Finland, whereas a modest increase is to be expected in Sweden. The calculations are performed in terms of domestic emissions alone, but the emission numbers in Estonia, Latvia, and Lithuania indicate that transboundary air pollution is also decreasing and pressure from external emissions to three Nordic countries is likely to decrease.

The analysis here is based on aggregative data as air pollution numbers comes at the country-specific level alone. The accuracy of the predictions here could be increased if data that are more detailed were applied. Amann et al. (2007), who provide $P M_{2.5}$ emissions in the largest cities in Europe, have currently provided such data. Further, an increase in the accuracy can be gained if technical progress is modeled, as its role in the future air-cleaning may be considerable. The current race against greenhouse cases is another topic of interest, since most studies suggest that traditional pollutants, such as particulate matter, decrease together with greenhouse gases since they both have their roots in energy combustion.

\section{References}

Amann, M., J. Cofala, Ch. Heyes, Zb. Klimont, M. Mechler, M. Posch and W. Schopp. 2004. The RAINS model. Documentation of the Model Approach Prepared for the RAINS Peer Review 2004. IIASA Interim Report, http://www.iiasa.ac.at/rains/review/review-full.pdf Amann, M., J. Cofala, Ch. Heyes, Zb. Klimont, M. Mechler and W. Schopp. 2007. Estimating Concentrations of Fine Particulate Matter in Urban Background Air of European Cities. IIASA Interim Report IR-007-01, http://www.iiasa.ac.at/rains/reports/IR-07-001-citydelta.pdf

Arrow K., B. Bolin,R. Costanza,P. Dasgupta, K. Folke,C.S. Holling, B.O.Jansson, S. Levin, K.G. Mäler, C. Perrings and D. Pimentel. 1995. Economic Growth, Carrying Capacity, and the Environment. Ecological Economics 15: 1591-1595.

Brunekreef, B. and S.T. Holgate. 2002. Air Pollution and Health. Lancet 360: 1233-1242. 
Chay, Y., C. Dopkin and M. Greenstone. 2003. The Clean Air Act of 1970 and Adult Mortality. Journal of Risk and Uncertainty 27(3): 279-300.

Chay, K.Y. and M. Greenstone. 2003. The Impact of Air Pollution on Infant Mortality: Evidence from Geographic Variation in Pollution Shocks Induced by a Recession. Quarterly Journal of Economics 118:1121-1167.

Cole M.A. and R.J.R. Elliot. 2003. Determining the Trade-Composition Effect: The Role of Capital, Labor, and Environmental Regulations. Journal of Environmental Economics and Management 46: 363-383.

Cole M.A. and R.J.R. Elliot. 2005. FDI and the Capital Intensity of "Dirty" Sectors: A Missing Piece of the Pollution Havens Puzzle. Review of Development Economics 9:530-548.

Currie, J. and M. Neidell. 2005. Air Pollution and Infant Health: What can we Learn from California's Recent Experience? Quarterly Journal of Economics 120: 1003-1030.

Heston, A., R. Summers and B. Aten. 2006. Penn World Table Version 6.2, Center for International Comparison of Production, Income and Prices at the University of Pennsylvania.

Kelly D.L. 2003. On Environmental Kuznets Curves Arising from Stock Externalities. Journal of Economic Dynamics and Control 27: 1367-1390.

Lehmijoki, U. and E. Rovenskaya. 2007. Optimal Pollution and Optimal Population, IIASA Interim Report IR-07-023.

Ostro, B. 2004. Outdoor Air Pollution: Assessing the Environmental Burden of Disease at National and Local Levels. WHO Environmental Burden of Disease Series 5.

Pasche, M. 2002. Technical Progress, Structural Change, and the Environmental Kuznets Curve. Ecological Economics 42: 381-389.

Pope, C.A., R.T. Burnett,M.J. Thun, E.E. Calle, D. Krewski, K. Ito and G.D. Thurston. 1992. Lung Cancer, Cardiopulmonary Mortality, and Long-term Exposure to Fine Particulate Air Pollution. Journal of the American Medical Association 287(9): 1132-1141.

Samet, J.M., F. Dominici, F.C. Curriero, I. Coursac and S.L. Zeger. 2000. Fine Particulate Air Pollution and Mortality in 20 U.S. Cities, 1987-1994. The New England Journal of Medicine 343: 1742-1749.

Stokey N.L. 1998. Are There Limits to Growth? International Economic Review, 39: $1-31$.

WHO. 2004. Meta-analysis of Time-series Studies and Panel Studies of Particulate Matter (PM) and Ozone (O3). World Health Organization, Regional Office for Europe, Copenhagen.

WHO. 2007. Country Profiles for Environmental Burden of Disease. World Health Organization, Regional Office for Europe, Copenhagen. New York. 
Appendix: Countries and Variables

\begin{tabular}{|c|c|c|c|c|c|c|c|}
\hline Country & EU & GDPpc & GDP & $\mathrm{PM}_{2.5}$ & Deaths & $\varnothing$ & $\eta$ \\
\hline Austria & 1995 & 27000 & 218.60 & 28.18 & 5508 & 0.129 & 195.45 \\
\hline Belgium & 1952 & 24662 & 254.11 & 32.86 & 12904 & 0.129 & 392.71 \\
\hline Cyprus & 2004 & 20457 & 15.51 & 2.18 & 231 & 0.141 & 106.04 \\
\hline Czech Rep. & 2004 & 13617 & 139.80 & 42.69 & 9086 & 0.305 & 212.85 \\
\hline Denmark & 1973 & 27827 & 148.59 & 25.97 & 3274 & 0.175 & 126.08 \\
\hline Estonia & 2004 & 11081 & 15.86 & 21.69 & 631 & 1.367 & 29.10 \\
\hline Finland & 1995 & 22741 & 117.72 & 28.26 & 1272 & 0.240 & 45.01 \\
\hline France & 1952 & 25045 & 1484.59 & 328.23 & 42202 & 0.221 & 128.57 \\
\hline Germany & 1952 & 25061 & 2063.66 & 159.86 & 75150 & 0.077 & 470.10 \\
\hline Greece & 1980 & 13982 & 153.46 & 47.32 & 7242 & 0.308 & 153.05 \\
\hline Hungary & 2004 & 11383 & 116.40 & 52.38 & 12895 & 0.450 & 246.19 \\
\hline Ireland & 1973 & 24948 & 94.84 & 14.16 & 1174 & 0.149 & 82.91 \\
\hline Italy & 1952 & 22487 & 1297.85 & 150.27 & 50766 & 0.116 & 337.83 \\
\hline Latvia & 2004 & 8998 & 21.64 & 10.93 & 1334 & 0.505 & 122.06 \\
\hline Lithuania & 2004 & 9161 & 33.17 & 12.5 & 2197 & 0.377 & 175.73 \\
\hline Luxembourg & 1952 & 48217 & 20.99 & 2.73 & 321 & 0.130 & 117.49 \\
\hline Malta & 2004 & 18863 & 7.39 & 0.59 & 193 & 0.080 & 326.95 \\
\hline Netherlands & 1952 & 26293 & 417.99 & 26.78 & 15573 & 0.064 & 581.52 \\
\hline Poland & 2004 & 8611 & 332.81 & 202.7 & 32944 & 0.609 & 162.52 \\
\hline Portugal & 1986 & 17323 & 177.13 & 76.99 & 5053 & 0.435 & 65.63 \\
\hline Slovak Rep. & 2004 & 9697 & 52.37 & 14.5 & 4265 & 0.277 & 294.13 \\
\hline Slovenia & 2004 & 18206 & 35.09 & 12.08 & 1582 & 0.344 & 130.96 \\
\hline Spain & 1986 & 19536 & 795.47 & 151.14 & 19976 & 0.190 & 132.17 \\
\hline Sweden & 1995 & 25232 & 223.99 & 25.4 & 3284 & 0.113 & 129.28 \\
\hline UK & 1973 & 24666 & 1447.17 & 109.4 & 39543 & 0.076 & 361.45 \\
\hline
\end{tabular}

Per capita GDP (GDPpc) in international dollars of 2000, GDP in billion international dollars of 2000, emissions in kilotons. The data refers to the year 2000 . 
